\title{
Dynamics of longitudinal growth in children with idiopathic rheumatoid arthritis in response to infliximab treatment
}

\author{
OU Konopelko ${ }^{*}$, ES Zholobova, OS Rozvadovskaya \\ From 18th Pediatric Rheumatology European Society (PReS) Congress \\ Bruges, Belgium. 14-18 September 2011
}

\section{Background}

Anti-tumor necrosis factor (TNF) - infliximab is known to decrease disease activity of juvenile idiopathic arthritis (JIA) but its effect on longitudinal growth in relation to puberty is not clear.

\section{Aim}

To assess the dynamics of longitudinal growth in prepubertal and pubertal patient's with JIA in response to infliximab, to evaluate effectiveness of the therapy.

\section{Materials and methods}

Study included 13 children, 8 of the prepubertal and 5 the puberty. The study was subjected to information about sex, age, children's growth, diagnosis, therapy. Growth was estimated by measuring and comparing patient's height standard deviation score(SDS) in relation to the midparental height, the change of this value $(\Delta \mathrm{hSDS})$ from -1 to 0 and 0 to 1 year of treatment and the change between the $\Delta$ hSDS values to assess growth improvement. Treatment efficacy was assessed according to criteria ACR pedi. Infliximab was administered in connection with ineffectiveness of standard antirheumatic therapy (methotrexate, leflunamide, cyclosporine A, methotrexate + cyclosporine A combination).

\section{Results}

9 of all 13 children $(69,2 \%)$ were with systemic JIA, 2 of all 13 children $(15,4 \%)$ - poliarticular JIA, other 2 of 13 children $(15,4 \%)$ - juvenile spondyloarthritis. Before infliximab theatment all children were with 3-2 degrees of

\footnotetext{
* Correspondence: olyako86@mail.ru

Department of Pediatric Rheumatology, Leuven, Belgium, First Moscow

Medical State University I.M. Sechenov, Moscow, Russian Federation
}

disease activity. After a year of infliximab 53.8\% of patients demonstrated response ACR pedi70, 30,8\% of patients ACR pedi $50,15,4 \%$ - ACR pedi 30 . In the prepubertal group the relation height SDS (mean \pm standart error of the mean) was $-1.53 \pm 1,-2.07 \pm 1$ and $1.45 \pm 1.61$ at $-1,0$ and 1 year of infliximab treatment respectively. The $\Delta \mathrm{hSDS}$ before infliximab was $-0.54 \pm 0.27$, over the first year with infliximab $\triangle \mathrm{hSDS}$ was $0.62 \pm 0.9(\mathrm{p}>0,05)$. In the pubertal group the SDS was- $1,39 \pm 2.36,-3.12 \pm 2.6$, and $-3.12 \pm 2.61$ at $-1,0$ and 1 year of treatment respectively. The $\Delta$ hSDS before infliximab was $-0.73 \pm 0.43$, over the first year with infliximab $\Delta$ hSDS was $-0.004 \pm 0.47$ $(p>0,05)$. Individual analysis of each patient revealed that most children of the pubertal group (3/5) and the prepubertal group (6/8) showed improvement in longitudinal growth during treatment with infliximab. Out of the 13 children included in the study prior to the infliximab, 8 received steroids per os. After a year of the treatment in therapy of 6 children doses of steroids were decreased and one child no longer needed steroids. The dose of steroids $\mathrm{mg} / \mathrm{kg} /$ day to 0 and 1 year of the therapy respectively was $0.22-0.1,0.12-0.1,0.1-0.076 \Delta$ dozy.

\section{Conclusions}

Infliximab treatment in addition to a significant therapeutic effect also showed an increase of longitudinal growth in children suffering from idiopathic rheumatoid arthritis.

Published: 14 September 2011

doi:10.1186/1546-0096-9-S1-P165

Cite this article as: Konopelko et al:: Dynamics of longitudinal growth in children with idiopathic rheumatoid arthritis in response to infliximab treatment. Pediatric Rheumatology 2011 9(Suppl 1):P165.

\section{Biomed Central}

(c) 2011 Konopelko et al; licensee BioMed Central Ltd. This is an open access article distributed under the terms of the Creative Commons Attribution License (http://creativecommons.org/licenses/by/2.0), which permits unrestricted use, distribution, and reproduction in any medium, provided the original work is properly cited. 